Abebe R. Tufa $\cdot$ H. Zegeye

\title{
An algorithm for finding a common point of the solutions of fixed point and variational inequality problems in Banach spaces
}

Received: 15 September 2014 / Accepted: 28 May 2015 / Published online: 17 June 2015

(C) The Author(s) 2015. This article is published with open access at Springerlink.com

\begin{abstract}
Let $C$ be a nonempty, closed and convex subset of a 2-uniformly convex and uniformly smooth real Banach space $E$. Let $T: C \rightarrow C$ be relatively nonexpansive mapping and let $A_{i}: C \rightarrow E^{*}$ be $L_{i}$-Lipschitz monotone mappings, for $i=1,2$. In this paper, we introduce and study an iterative process for finding a common point of the fixed point set of a relatively nonexpansive mapping and the solution set of variational inequality problems for $A_{1}$ and $A_{2}$. Under some mild assumptions, we show that the proposed algorithm converges strongly to a point in $F(T) \cap V I\left(C, A_{1}\right) \cap V I\left(C, A_{2}\right)$. Our theorems improve and unify most of the results that have been proved for this important class of nonlinear operators.
\end{abstract}

Mathematics Subject Classification 47H09 - 47H10 - 65J15

لتكن C مجمو عة جزئية غير خالية، مغلقة ومحدبة من فضاء باناخ حقيقي 2-محدب بشكل منتظم وأملس بشكل منتظم E. ليكن متمدد نسبيا وليكن *

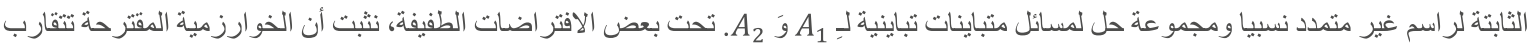
إلى نقطة في $)$ F

\section{Introduction}

Let $C$ be a nonempty subset of a real Banach space $E$. A mapping $T: C \rightarrow E$ is called L-Lipschitz if there exits $L \geq 0$ such that

$$
|| T x-T y|\leq L| \mid x-y \|, \quad \forall x, y \in C .
$$

If $L<1$, then $T$ is called a contraction and if $L=1$ then $T$ is called a nonexpansive mapping. It follows that the class of Lipschitzian mappings includes the class of nonexpansive and hence the class of contraction mappings.

A mapping $A$ of $C$ into $E^{*}$ is called monotone if

$$
\langle A x-A y, x-y\rangle \geq 0, \text { for all } x, y \in C .
$$

$A$ is called $\alpha$-strongly monotone, if there exists a positive real number $\alpha$ such that

A. R. Tufa $\cdot H$. Zegeye $(\varangle)$

Department of Mathematics, University of Botswana, Pvt. Bag 00704, Gaborone, Botswana

E-mail: habtuzh@yahoo.com

A. R. Tufa

E-mail: abykabe@yahoo.com 


$$
\langle A x-A y, x-y\rangle \geq \alpha\|x-y\|^{2}, \quad \text { for all } \quad x, y \in C .
$$

$A$ is called $\gamma$-inverse strongly monotone, if there exists a positive real number $\gamma$ such that

$$
\langle A x-A y, x-y\rangle \geq \gamma\|A x-A y\|^{2}, \quad \text { for all } \quad x, y \in C .
$$

We observe that any $\gamma$-inverse strongly monotone mapping $A$ is Lipschitz with $L=\frac{1}{\gamma}$.

Clearly, the class of monotone mappings includes the classes of $\alpha$-strongly monotone and $\gamma$-inverse strongly monotone mappings.

Let $C$ be a nonempty, closed and convex subset of $E$ and let $A: C \rightarrow E^{*}$ be a nonlinear mapping. The variational inequality problem, denoted by VIP, is to find $x^{*} \in C$ such that

$$
\left\langle A x^{*}, x-x^{*}\right\rangle \geq 0, \quad \forall x \in C .
$$

The solution set of the variational inequality problem is denoted by $\operatorname{VI}(C, A)$. The variational inequality problem is a fundamental problem in variational analysis. The theory of variational analysis has emerged as a very natural generalization of the theory of boundary value problems and allows us to consider new problems arising from many fields of applied mathematics, such as mechanics, physics, engineering, the theory of convex programming, and the theory of control: see, for instance [16,18,25,28-30,33].

There are several iterative methods for solving VIP (see, e.g., $[4,5,7,11,18,30,33,35])$. The basic idea consists of extending the projected gradient method for solving the problem of minimizing $f(x)$ subject to $x \in C$ given by

$$
x_{n+1}=P_{C}\left[x_{n}-\alpha_{n} \nabla f\left(x_{n}\right)\right], \quad n \geq 0,
$$

where $\left\{\alpha_{n}\right\}$ is a positive real sequence satisfying certain conditions and $P_{C}$ is the metric projection onto $C$. For convergence properties of this method for the case in which $f: \mathbb{R}^{2} \rightarrow \mathbb{R}$ is convex and differentiable function, one may see [2]. An immediate extension of method (1.6) to VIP is the projected gradient method for optimization problems, substituting the operator $A$ for the gradient, so that we generate a sequence $\left\{x_{n}\right\}$ through:

$$
x_{n+1}=P_{C}\left[x_{n}-\alpha_{n} A x_{n}\right], \quad n \geq 0 .
$$

Convergence results for this method require some monotonicity properties of $A$. This method converges under quite strong hypotheses. If $A$ is Lipschitz continuous with Lipschitz constant $L$ and $\alpha$-strongly monotone, then the sequence generated by (1.7) converges to an element of $\operatorname{VI}(C, A)$, if $\left\{\alpha_{n}\right\} \subset\left(0,2 \alpha / L^{2}\right)$ provided that problem (1.5) has a solution.

We note that, in (1.7), there is no chance of relaxing the assumption on $A$ to plain monotonicity. For example consider $C=\mathbb{R}^{2}$ and $A$, a rotation with a $\frac{\pi}{2}$ angle, which is certainly monotone and Lipschitz continuous with $\operatorname{VI}(C, A)=\{0\}$. It is easy to check that $\left\|x_{n+1}\right\|>\left\|x_{n}\right\|$ for all $n \geq 0$ and for all $\alpha_{n}>0$. Therefore, the sequence generated by (1.7) moves away from the solution, independent of the choice of the sequence $\alpha_{n}$.

To deal with the weakness of the method defined by (1.7), Korpelevich [14] proposed a modification of the method, called the extragradient algorithm in the finite-dimensional Euclidean space $\mathbb{R}^{n}$ under the assumption that a set $C \subset \mathbb{R}^{n}$ is closed and convex and a mapping $A$ of $C$ into $\mathbb{R}^{n}$ is monotone and $L$-Lipschitz continuous,

$$
\left\{\begin{array}{l}
y_{n}=P_{C}\left[x_{n}-\lambda A x_{n}\right], \\
x_{n+1}=P_{C}\left[x_{n}-\lambda A y_{n}\right], \quad n \geq 0
\end{array}\right.
$$

for all $n \geq 0$, where $\lambda \in\left(0, \frac{1}{L}\right)$. He proved that the sequences $\left\{x_{n}\right\}$ and $\left\{y_{n}\right\}$, generated by (1.8), converge strongly to point $x^{*} \in \operatorname{VI}(C, A)$ provided that $\mathrm{VI}(C, A)$ is nonempty.

The difference in (1.8) is that $A$ is evaluated twice and the projection is computed twice at each iteration, but the benefit is significant, because the resulting algorithm is applicable to the whole class of variational inequalities for monotone mappings. The method of solving VIP by Korpelevichs has received great attention by many authors (see, e.g., $[7,11,16,17,22,30,36,37]$ and the references therein).

In 2006, Nadezhkina and Takahashi [17] suggested the following modified Korpelevichs method for a solution of VIP for $L$-Lipschitz continuous monotone mapping $A$ in infinite-dimensional Hilbert spaces. Let $\left\{x_{n}\right\}$ be a sequence generated from an arbitrary $x_{0} \in C$ by

$$
\left\{\begin{array}{l}
x_{0} \in C \\
y_{n}=P_{C}\left[x_{n}-\lambda_{n} A x_{n}\right] \\
x_{n+1}=\alpha_{n} x_{n}+\left(1-\alpha_{n}\right) P_{C}\left[x_{n}-\lambda_{n} A y_{n}\right], \quad n \geq 0
\end{array}\right.
$$


where $P_{C}$ is a metric projection from $H$ onto $C,\left\{\lambda_{n}\right\} \subset[a, b]$ for some $a, b \in(0,1 / L)$ and $\left\{\alpha_{n}\right\} \subset[c, d]$ for some $c, d \in(0,1)$. Then, they proved that the sequence $\left\{x_{n}\right\}$ converges weakly to an element of $\operatorname{VI}(C, A)$.

However, we realize that Korpelevichs modified method (1.9) has only weak convergence in the infinitedimensional Hilbert spaces (you may also see, e.g., [6,7]). Therefore, several authors studied to obtain strong convergence by modifying the original method of Korpelevich. For example, in [4,9,31], it is proved that some very interesting Korpelevich-type algorithms strongly converge to a solution of VIP.

Recently, Yao et al. [32] investigated the problem of finding a solution of variational inequality problem for $\gamma$-inverse strongly monotone mapping $A$, by considering the following iterative algorithm:

$$
\left\{\begin{array}{l}
y_{n}=P_{C}\left[x_{n}-\lambda_{n} A x_{n}+\alpha_{n}\left(f\left(x_{n}\right)-x_{n}\right)\right], \\
x_{n+1}=P_{C}\left[x_{n}-\mu_{n} A y_{n}+\gamma_{n}\left(y_{n}-x_{n}\right)\right], \quad n \geq 0
\end{array}\right.
$$

where $f: C \rightarrow H$ is a $\rho$-contractive mapping and $\left\{\alpha_{n}\right\},\left\{\lambda_{n}\right\},\left\{\mu_{n}\right\}$ and $\left\{\gamma_{n}\right\}$ are real sequences satisfying certain conditions. Then, they proved that the sequence $\left\{x_{n}\right\}$ generated by (1.10) converges strongly to $x^{*} \in$ $\mathrm{VI}(C, A)$.

More recently, Zegeye and Shahzad [38] investigated the problem of finding a common solution of a finite family of variational inequality problems for Lipschitz monotone mappings in Hilbert spaces. In fact, they proved the following theorem.

Theorem ZS Let C be a nonempty, closed and convex subset of a real Hilbert space $H$. Let $A_{i}: C \rightarrow H$ be an $L_{i}$-Lipschitz monotone mappings with Lipschitz constants $L_{i}$, for $i=1,2$. Let $f: C \rightarrow C$ be a contraction mapping. Assume that $\mathcal{F}=V I\left(C, A_{1}\right) \cap V I\left(C, A_{2}\right)$ is nonempty. Let $\left\{x_{n}\right\}$ be a sequence generated from an arbitrary $x_{0} \in C$ by

$$
\left\{\begin{aligned}
z_{n}= & P_{C}\left[x_{n}-\gamma_{n} A_{2} x_{n}\right], \\
y_{n}= & P_{C}\left[x_{n}-\gamma_{n} A_{1} x_{n}\right], \\
& x_{n+1}=\alpha_{n} f\left(x_{n}\right)+\left(1-\alpha_{n}\right)\left(a_{n} x_{n}+b_{n} P_{C}\left[x_{n}-\gamma_{n} A_{1} y_{n}\right]\right. \\
& \left.+c_{n} P_{C}\left[x_{n}-\gamma_{n} A_{2} z_{n}\right]\right),
\end{aligned}\right.
$$

where $P_{C}$ is the metric projection from $H$ onto $C$, and $\left\{\gamma_{n}\right\rangle,\left\{a_{n}\right\},\left\{b_{n}\right\},\left\{c_{n}\right\}$ and $\left\{\alpha_{n}\right\}$ are real sequences satisfying certain conditions. Then, $\left\{x_{n}\right\}$ converges strongly to a point $x^{*} \in \mathcal{F}$.

We observe that the strong convergence result in [38] is valid only in Hilbert spaces. This now leads to the following important question.

Question 1 Can we obtain an iterative scheme which converges strongly to a point in $V I(C, A)$ in more general Banach spaces?

It is well known that if $C$ is a nonempty closed convex subset of a Hilbert space $H$ the metric projection $P_{C}: H \rightarrow C$ is nonexpansive. This fact actually characterizes Hilbert spaces and consequently, it is not available in more general Banach spaces. Recently, Alber [1] introduced a generalized projection operator $\Pi_{C}$ in a Banach space $E$ which is an analogue of the metric projection in Hilbert spaces.

Let $E$ be a smooth real Banach space with dual $E^{*}$. Let the Lyapunov functional $\phi: E \times E \rightarrow \mathbb{R}$, introduced by Alber [1], be defined by

$$
\phi(y, x)=\|y\|^{2}-2\langle y, J x\rangle+\|x\|^{2}, \quad \text { for } \quad x, y \in E,
$$

where $J$ is the normalized duality mapping from $E$ into $2^{E^{*}}$ defined by $J x:=\left\{f^{*} \in E^{*}:\left\langle x, f^{*}\right\rangle=\|x\|^{2}=\right.$ $\left.\left\|f^{*}\right\|^{2}\right\}$, where $\langle\cdot, \cdot\rangle$ denotes the generalized duality pairing. It is well known that $E$ is smooth if and only if $J$ is single valued and if $E$ is uniformly smooth, then $J$ is uniformly continuous on bounded subsets of $E$. In addition, if $E$ is a reflexive and strictly convex Banach space with a strictly convex dual, then $J^{-1}$ is duality mapping from $E^{*}$ into $E$ which is single valued, one-to-one, surjective and $J J^{-1}=I_{E^{*}}$ and $J^{-1} J=I_{E}$ (see [24]). We note that in a Hilbert space, $H, J$ is the identity mapping.

Let $C$ be a subset of a smooth real Banach space $E$. The generalized projection $\Pi_{C}: E \rightarrow C$, introduced by Alber [1], is a mapping that assigns to an arbitrary point $x \in E$ the minimum point of the function $\phi(y, x)$, that is $\Pi_{C} x=\bar{x}$, where $\bar{x}$ is the solution to the minimization problem: $\inf _{y \in C} \phi(y, x)$.

It is known that, if $C$ is nonempty, closed and convex subset of a real reflexive, strictly convex, and smooth Banach space $E$ and $x \in E$, then there exists a unique element $x_{0} \in C$ such that $\phi\left(x_{0}, x\right)=\min \{\phi(z, x)$ : $z \in C\}$ (see, e.g [1]).

From the definition of $\phi$, we have that 


$$
\begin{gathered}
(\|x\|-\|y\|)^{2} \leq \phi(x, y) \leq(\|x\|+\|y\|)^{2}, \\
\phi(x, y)=\phi(x, z)+\phi(z, y)+2\langle x-z, J z-J y\rangle .
\end{gathered}
$$

If $E$ is a Hilbert space, then $\phi(y, x)=\|y-x\|^{2}$ and $\Pi_{C}=P_{C}$ is the metric projection of $H$ onto $C$.

Let $T$ be a mapping from $C$ into itself. A point $x \in C$ is a fixed point of $T$ if $T x=x$ and we denote by $F(T)$ the set of fixed points of $T$; that is, $F(T)=\{x \in C: T x=x\}$. A point $p$ in $C$ is said to be an asymptotic fixed point of $T$ (see [19]) if $C$ contains a sequence $\left\{x_{n}\right\}$ which converges weakly to $p$ such that $\lim _{n \rightarrow \infty}\left\|x_{n}-T x_{n}\right\|=0$. The set of asymptotic fixed points of $T$ will be denoted by $\widehat{F}(T)$. A mapping $T$ from $C$ into itself is called relatively nonexpansive if (R1) $F(T) \neq \emptyset$; (R2) $\phi(p, T x) \leq \phi(p, x)$ for $x \in C$ and (R3) $F(T)=\widehat{F}(T)$.

Clearly, if $E=H$, a real Hilbert space, then the class of relatively nonexpansive mappings includes the class of nonexpansive and hence contraction mappings with nonempty fixed point set.

Many authors have considered the problem of finding a common element of the fixed point set of a relatively nonexpansive mapping and the solution set of a variational inequality problem for $\gamma$-inverse strongly monotone mapping (see, e.g., $[13,15,20,23,26,34])$.

For finding an element of $F(T) \bigcap \hat{\mathrm{A}}^{\prime} \mathrm{VI}(C, A)$ under the assumption that a set $C$ is closed and convex subset of $H$, where $H$ is a real Hilbert space, $T$ is nonexpansive mapping of $C$ into itself, and $A$ is Lipschitz monotone mapping of $C$ into $H$, Nadezhkina and Takahashi [17], introduced the following iterative process.

$$
\left\{\begin{array}{l}
x_{0} \in C, \text { chosen arbitrary, } \\
y_{n}=P_{C}\left(x_{n}-\lambda_{n} A x_{n}\right), \\
x_{n+1}=\alpha_{n} x_{n}+\left(1-\alpha_{n}\right) T P_{C}\left[x_{n}-\lambda_{n} A y_{n}\right] .
\end{array}\right.
$$

They proved that the sequences $\left\{x_{n}\right\}$ and $\left\{y_{n}\right\}$ converge weakly to the same element of $F(T) \hat{\mathrm{A}}^{\prime} \cap V I(C, A)$.

In [10], Iiduka and Takahashi proposed the iteration scheme given by

$$
\left\{\begin{array}{l}
x_{0}=x \in C, \text { chosen arbitrary, } \\
x_{n+1}=\alpha_{n} x+\left(1-\alpha_{n}\right) T P_{C}\left[x_{n}-\lambda_{n} A x_{n}\right]
\end{array}\right.
$$

where $A$ is $\gamma$-inverse strongly monotone, $\left\{\alpha_{n}\right\}$ is a sequence in $(0,1)$, and $\left\{\lambda_{n}\right\}$ is a sequence in $(0,2 \gamma)$ satisfying certain conditions. They showed that if $F(T) \bigcap \operatorname{VI}(C, A)$ is nonempty, then the sequence $\left\{x_{n}\right\}$ converges strongly to some $z \in F(T) \bigcap \operatorname{VI}(C, A)$.

Very recently, Zegeye et al. [33] introduced and studied the iterative scheme given below for a common point of the solution set of a variational inequality problem for $\gamma$-inverse strongly monotone mapping $A$ and the fixed point set of a closed relatively quasi-nonexpansive mapping $T$ in a 2-uniformly convex and uniformly smooth real Banach space $E$ :

$$
\left\{\begin{array}{l}
x_{0} \in C=C_{1}, \quad \text { chosen arbitrary, } \\
z_{n}=\Pi_{C}\left(J^{-1}\left(J x_{n}-\lambda_{n} A x_{n}\right)\right) \\
y_{n}=J^{-1}\left(\beta J x_{n}-(1-\beta) J T z_{n}\right) \\
C_{n+1}=\left\{z \in C_{n}: \phi\left(z, y_{n}\right) \leq \phi\left(z, x_{n}\right)\right\} \\
x_{n+1}=\Pi_{C_{n+1}}\left(x_{0}\right), n \geq 0
\end{array}\right.
$$

where $C$ is a closed convex nonempty subset of $E$ and $\left\{\lambda_{n}\right\}$ is a sequence satisfying certain conditions. They proved that the sequence $\left\{x_{n}\right\}$ converges strongly to an element of $F:=F(T) \bigcap \operatorname{VI}(C ; A) \neq \emptyset$ provided that $A$ satisfies $\|A x\| \leq\|A x-A p\|$ for all $x \in C$ and $p \in F$.

This brings us to our second question.

Question 2 Can we obtain an iterative scheme which converges strongly to a common point of the fixed point set of a relatively nonexpansive mapping $T$ and the solution of a variational inequality problem for Lipschitz monotone mapping A in Banach spaces?

It is our purpose in this paper to propose an extragradient-type method for finding a common point of the fixed point set of a relatively nonexpansive mapping $T$ and the solution set of two variational inequality problems for Lipschitz monotone mappings in a 2-uniformly convex and uniformly smooth real Banach space $E$. As a consequence, we obtain a convergence theorem for approximating a common point of the solution of a finite family of variational inequality problems for Lipschitz monotone mappings. The results obtained in this paper improve and extend the results of Zegeye and Shahzad [38], Yao et al. [32] and some other results in this direction. 


\section{Preliminaries}

Let $E$ be a real Banach space. Let $S(E)=\{x \in E:\|x\|=1\}$. Then the norm of $E$ is said to be Gâteaux differentiable if

$$
\lim _{t \rightarrow 0} \frac{\|x+t y\|-\|x\|}{t},
$$

exists for each $x, y \in S(E)$. In this case, $E$ is called smooth (see e.g., [24]).

The modulus of smoothness of $E$ is defined by

$$
\rho_{E}(\tau):=\sup \left\{\frac{\|x+y\|+\|x-y\|}{2}-1:\|x\|=1,\|y\|=\tau\right\} .
$$

A Banach space $E$ is called uniformly smooth if $\lim _{\tau \rightarrow 0} \frac{\rho_{E}(\tau)}{\tau}=0$. It is well known that every uniformly smooth space (e.g., $L_{p}$ and the Sobolev spaces $W_{p}^{m},(1<p \stackrel{\tau}{<} \infty)$ ) has Gâteaux differentiable norm (see e.g., [8]).

A normed space $E$ is called strictly convex if for all $x, y \in E$ such that $\|x\|=\|y\|=1, x \neq y$, $\left\|\frac{x+y}{2}\right\|<1$.

The modulus of convexity of $E$ is the function $\sigma:(0,2] \rightarrow[0,1]$ defined by $\sigma(\epsilon)=\inf \left\{1-\left\|\frac{x+y}{2}\right\|:\|x\|\right.$ $=1=\|y\| ; \epsilon=\|x-y\|\}$.

$E$ is called uniformly convex if and only if $\sigma(\epsilon)>0$, for every $\epsilon \in(0,2]$. Clearly, every uniformly convex is strictly convex space.

Let $p>0$. Then $E$ is said to be $p$-uniformly convex if there exists a constant $c>0$ such that $\sigma(\epsilon) \geq c \epsilon^{p}$, for all $\epsilon \in(0,2]$. It is well known (see for example [27]) that

$$
\mathrm{七}_{p} \text { or } \mathrm{1}_{p}= \begin{cases}p \text {-uniformly convex } & \text { if } p \geq 2 \\ 2 \text {-uniformly convex } & \text { if } 1<p \leq 2\end{cases}
$$

A monotone mapping $B: C \rightarrow 2^{E^{*}}$ is called maximal monotone if its graph $G(B)$ is not properly contained in the graph of any other monotone mapping. It is clear that a monotone mapping $B$ is maximal if and only if for any $(x, u) \in E \times E^{*}$, if $\langle x-y, u-v\rangle \geq 0$, for every $(y, v) \in G(B)$, then it follows that $u \in B x$. Let $A$ be a monotone and $L$-Lipschitz mapping of $C$ into $E^{*}$ and let $N_{C} v$ be the normal cone to $C$ at $v \in C$; i.e.,

$$
N_{C} v=\left\{w \in E^{*}:\langle v-u, w\rangle \geq 0, \forall u \in C\right\}
$$

Define

$$
B v= \begin{cases}A v+N_{C} v, & \text { if } \quad v \in C, \\ \emptyset, & \text { if } v \notin C .\end{cases}
$$

Then, $B$ is maximal monotone and $0 \in B v$ if and only if $v \in V I(C, A)$ (see, e.g., [21]).

In the sequel, we shall make use of the following lammas.

Lemma 2.1 ([35]) Let $C$ be a non-empty closed and convex subset of a real reflexive, strictly convex and smooth Banach space E. If $A: C \rightarrow E^{*}$ is continuous monotone mapping, then $V I(C, A)$ is closed and convex.

Lemma 2.2 ([1]) Let C be a non-empty closed and convex subset of a real reflexive, strictly convex and smooth Banach space E. Then for $\forall y \in C$,

$$
\phi\left(y, \Pi_{C} x\right)+\phi\left(\Pi_{C} x, x\right) \leq \phi(y, x) .
$$

We make use of the function $V: E \times E^{*} \rightarrow \mathbb{R}$ defined by $V\left(x, x^{*}\right)=\|x\|^{2}-2\left\langle x, x^{*}\right\rangle+\left\|x^{*}\right\|^{2}$ for all $x \in E$ and $x^{*} \in E^{*}$, studied by Alber [1]. That is $V\left(x, x^{*}\right)=\phi\left(x, J^{-1} x^{*}\right)$ for all $x \in E$ and $x^{*} \in E^{*}$.

Lemma 2.3 ([1]) Let $E$ be reflexive strictly convex and smooth Banach space with $E^{*}$ as its dual.Then, $V\left(x, x^{*}\right)+2\left\langle J^{-1} x^{*}-x, y^{*}\right\rangle \leq V\left(x, x^{*}+y^{*}\right)$ for all $x \in E$ and $x^{*}, y^{*} \in E^{*}$. 
Lemma 2.4 ([1]) Let $C$ be a nonempty, closed and convex subset of a real smooth Banach space $E$ and $x \in E$. Then, $x_{0}=\Pi_{C} x$ if and only if

$$
\left\langle z-x_{0}, J x-J x_{0}\right\rangle \leq 0, \quad \forall z \in C .
$$

Lemma 2.5 ([3]) Suppose that $E$ is 2-uniformly convex Banach space.

Then, there exists $\mu \geq 1$ such that $\frac{1}{\mu}\|x-y\|^{2} \leq \phi(x, y)$ for all $x, y \in E$.

Lemma 2.6 ([33]) Let $E$ be a uniformly convex Banach space and $B_{R}(0)$ be a closed ball of $E$. Then, there exists a continuous strictly increasing convex function $g:[0, \infty) \rightarrow[0, \infty)$ with $g(0)=0$ such that

$$
\left\|\alpha_{0} x_{0}+\alpha_{1} x_{1}+\alpha_{2} x_{2}+\cdots+\alpha_{k} x_{k}\right\|^{2} \leq \sum_{i=0}^{k} \alpha_{i}\left\|x_{i}\right\|^{2}-\alpha_{i} \alpha_{j} g\left(\left\|x_{i}-x_{j}\right\|\right),
$$

where $0 \leq i \leq j \leq k$, for each $\alpha_{i} \in(0,1)$ and for $x_{i} \in B_{R}(0):=\{x \in E:\|x\| \leq R\}, i=0,1,2, \ldots, k$ with $\sum_{i=0}^{k} \alpha_{i}=1$.

Lemma 2.7 ([12]) Let $E$ be a real smooth and uniformly convex Banach space and let $\left\{x_{n}\right\}$ and $\left\{y_{n}\right\}$ be two sequences of $E$. If either $\left\{x_{n}\right\}$ or $\left\{y_{n}\right\}$ is bounded and $\phi\left(x_{n}, y_{n}\right) \rightarrow 0$ as $n \rightarrow \infty$, then $x_{n}-y_{n} \rightarrow 0$ as $n \rightarrow \infty$.

Remark 2.8 For any bounded sequences $\left\{x_{n}\right\}$ and $\left\{y_{n}\right\}$ in a 2-uniformly convex and uniformly smooth real Banach space $E$ we have

$$
x_{n}-y_{n} \rightarrow 0 \Leftrightarrow \phi\left(x_{n}, y_{n}\right) \rightarrow 0 \quad \text { as } \quad n \rightarrow \infty .
$$

Lemma 2.9 ([28]) Let $\left\{a_{n}\right\}$ be a sequence of nonnegative real numbers satisfying the following relation:

$$
a_{n+1} \leq\left(1-\alpha_{n}\right) a_{n}+\alpha_{n} \delta_{n}, n \geq n_{0},
$$

where $\left\{\alpha_{n}\right\} \subset(0,1)$ and $\left\{\delta_{n}\right\} \subset R$ satisfying the following conditions:

$\lim _{n \rightarrow \infty} \alpha_{n}=0, \sum_{n=1}^{\infty} \alpha_{n}=\infty$, and $\limsup _{n \rightarrow \infty} \delta_{n} \leq 0$. Then, $\lim _{n \rightarrow \infty} a_{n}=0$.

Lemma 2.10 ([16]) Let $\left\{a_{n}\right\}$ be sequences of real numbers such that there exists a subsequence $\left\{n_{i}\right\}$ of $\{n\}$ such that $a_{n_{i}}<a_{n_{i}+1}$, for all $i \in \mathbb{N}$. Then there exists a nondecreasing sequence $\left\{m_{k}\right\} \subset \mathbb{N}$ such that $m_{k} \rightarrow \infty$ and the following properties are satisfied by all (sufficiently large) numbers $k \in \mathbb{N}$ :

$$
a_{m_{k}} \leq a_{m_{k}+1} \text { and } a_{k} \leq a_{m_{k}+1} .
$$

In fact, $m_{k}=\max \left\{j \leq k: a_{j}<a_{j+1}\right\}$.

For the rest of this paper, $\Pi_{C}$ is a generalized metric projection from $E$ onto $C, \mu$ is a constant as in Lemma 2.5 and $\left\{\alpha_{n}\right\} \subset(0, c] \subset(0,1)$ for all $n \geq 0$ satisfying $\lim _{n \rightarrow \infty} \alpha_{n}=0$ and $\sum \alpha_{n}=\infty$.

\section{Main result}

Theorem 3.1 Let $C$ be a nonempty, closed and convex subset of a 2-uniformly convex and uniformly smooth real Banach space E. Let $A_{i}: C \rightarrow E^{*}$ be $L_{i}$-Lipschitzmonotone mappings with Lipschitz constants $L_{i}$, for $i=$ 1, 2. Let $T: C \rightarrow C$ be relatively nonexpansive mapping. Assume that $\mathcal{F}=V I\left(C, A_{1}\right) \cap \operatorname{VI}\left(C, A_{2}\right) \cap F(T)$ is nonempty. Let $\left\{x_{n}\right\}$ be a sequence generated from an arbitrary $x_{0}, u \in C$ by

$$
\left\{\begin{array}{l}
z_{n}=\Pi_{C} J^{-1}\left[J x_{n}-\gamma_{n} A_{2} x_{n}\right], \\
y_{n}=\Pi_{C} J^{-1}\left[J x_{n}-\gamma_{n} A_{1} x_{n}\right], \\
w_{n}=a_{n} J x_{n}+b_{n} J T x_{n}+c_{n} J\left(u_{n}\right)+d_{n} J\left(v_{n}\right), \\
x_{n+1}=\Pi_{C} J^{-1}\left[\alpha_{n} J u+\left(1-\alpha_{n}\right) w_{n}\right]
\end{array}\right.
$$

where $u_{n}=\Pi_{C} J^{-1}\left[J x_{n}-\gamma_{n} A_{1} y_{n}\right], v_{n}=\Pi_{C} J^{-1}\left[J x_{n}-\gamma_{n} A_{2} z_{n}\right],\left\{\gamma_{n}\right\} \subset[a, b] \subset\left(0, \frac{1}{\mu L}\right)$, for $L:=$ $\max \left\{L_{1}, L_{2}\right\}$ and $\left\{a_{n}\right\},\left\{b_{n}\right\},\left\{c_{n}\right\},\left\{d_{n}\right\} \subset[e, 1) \subset(0,1)$ such that $a_{n}+b_{n}+c_{n}+d_{n}=1$. Then, $\left\{x_{n}\right\}$ converges strongly to a point $x^{*}$ in $\mathcal{F}$ which is nearest to $u$ with respect to the Lyapunov distance. 
Proof Let $p \in \mathcal{F}$. Then, by (3.1), Lemma 2.2 and the monotonicity of $A_{1}$ we have

$$
\begin{aligned}
\phi\left(p, u_{n}\right)= & \phi\left(p, \Pi_{C} J^{-1}\left(J x_{n}-\gamma_{n} A_{1} y_{n}\right)\right) \\
\leq & \phi\left(p, J^{-1}\left(J x_{n}-\gamma_{n} A_{1} y_{n}\right)\right)-\phi\left(u_{n}, J^{-1}\left(J x_{n}-\gamma_{n} A_{1} y_{n}\right)\right) \\
= & \|p\|^{2}-2\left\langle p, J x_{n}-\gamma_{n} A_{1} y_{n}\right\rangle+\left\|J x_{n}-\gamma_{n} A_{1} y_{n}\right\|^{2} \\
& -\left[\left\|J x_{n}-\gamma_{n} A_{1} y_{n}\right\|^{2}-2\left\langle u_{n}, J x_{n}-\gamma_{n} A_{1} y_{n}\right\rangle+\left\|u_{n}\right\|^{2}\right] \\
= & \|p\|^{2}-2\left\langle p, J x_{n}\right\rangle+\left\|x_{n}\right\|^{2}-\left\|x_{n}\right\|^{2}+2\left\langle p, \gamma_{n} A_{1} y_{n}\right\rangle \\
& +2\left\langle u_{n}, J x_{n}\right\rangle-\left\|u_{n}\right\|^{2}-2\left\langle u_{n}, \gamma_{n} A_{1} y_{n}\right\rangle \\
= & \phi\left(p, x_{n}\right)-\phi\left(u_{n}, x_{n}\right)+2\left\langle p-u_{n}, \gamma_{n} A_{1} y_{n}\right\rangle \\
= & \phi\left(p, x_{n}\right)-\phi\left(u_{n}, x_{n}\right)+2\left\langle p-y_{n}, \gamma_{n} A_{1} y_{n}\right\rangle+2\left\langle y_{n}-u_{n}, \gamma_{n} A_{1} y_{n}\right\rangle \\
= & \phi\left(p, x_{n}\right)-\phi\left(u_{n}, x_{n}\right)+2 \gamma_{n}\left\langle p-y_{n}, A_{1} y_{n}-A_{1} p\right\rangle+2 \gamma_{n}\left\langle p-y_{n}, A_{1} p\right\rangle \\
& +2 \gamma_{n}\left\langle y_{n}-u_{n}, A_{1} y_{n}\right\rangle \\
\leq & \phi\left(p, x_{n}\right)-\phi\left(u_{n}, x_{n}\right)+2 \gamma_{n}\left\langle y_{n}-u_{n}, A_{1} y_{n}\right\rangle,
\end{aligned}
$$

and from (1.14), we obtain

$$
\phi\left(u_{n}, x_{n}\right)=\phi\left(u_{n}, y_{n}\right)+\phi\left(y_{n}, x_{n}\right)+2\left\langle u_{n}-y_{n}, J y_{n}-J x_{n}\right\rangle .
$$

Thus, from (3.2) and (3.3) we get

$$
\begin{aligned}
\phi\left(p, u_{n}\right) \leq & \phi\left(p, x_{n}\right)-\phi\left(u_{n}, y_{n}\right)-\phi\left(y_{n}, x_{n}\right) \\
& +2\left\langle y_{n}-u_{n}, \gamma_{n} A_{1} y_{n}-J x_{n}+J y_{n}\right\rangle .
\end{aligned}
$$

Moreover, by Lemma 2.4, we have that,

$$
\begin{aligned}
\left\langle y_{n}-u_{n}, \gamma_{n} A_{1} y_{n}-J x_{n}+J y_{n}\right\rangle= & \left\langle u_{n}-y_{n} \gamma_{n} A_{1} x_{n}-\gamma_{n} A_{1} y_{n}\right\rangle \\
& +\left\langle u_{n}-y_{n}, J x_{n}-\gamma_{n} A_{1} x_{n}-J y_{n}\right\rangle \\
\leq & \gamma_{n}\left\langle u_{n}-y_{n}, A_{1} x_{n}-A_{1} y_{n}\right\rangle .
\end{aligned}
$$

Then, since $A_{1}$ is Lipschitz, by (3.4) and (3.5), we have that,

$$
\begin{aligned}
\phi\left(p, u_{n}\right) \leq & \phi\left(p, x_{n}\right)-\phi\left(u_{n}, y_{n}\right)-\phi\left(y_{n}, x_{n}\right) \\
& +2 \gamma_{n}\left\langle u_{n}-y_{n}, A_{1} x_{n}-A_{1} y_{n}\right\rangle \\
\leq & \phi\left(p, x_{n}\right)-\phi\left(u_{n}, y_{n}\right)-\phi\left(y_{n}, x_{n}\right)+2 \gamma_{n}\left\|u_{n}-y_{n}\right\|\left\|A_{1} x_{n}-A_{1} y_{n}\right\| \\
\leq & \phi\left(p, x_{n}\right)-\phi\left(u_{n}, y_{n}\right)-\phi\left(y_{n}, x_{n}\right)+2 L \gamma_{n}\left\|u_{n}-y_{n}\right\|\left\|x_{n}-y_{n}\right\| \\
\leq & \phi\left(p, x_{n}\right)-\phi\left(u_{n}, y_{n}\right)-\phi\left(y_{n}, x_{n}\right)+L \gamma_{n}\left[\left\|u_{n}-y_{n}\right\|^{2}+\left\|x_{n}-y_{n}\right\|^{2}\right] .
\end{aligned}
$$

Hence, from (3.6) and Lemma 2.5 we have,

$$
\begin{aligned}
\phi\left(p, u_{n}\right) \leq & \phi\left(p, x_{n}\right)-\frac{1}{\mu}\left\|y_{n}-x_{n}\right\|^{2}-\frac{1}{\mu}\left\|u_{n}-y_{n}\right\|^{2} \\
& +L \gamma_{n}\left[\left\|u_{n}-y_{n}\right\|^{2}+\left\|x_{n}-y_{n}\right\|^{2}\right] \\
\leq & \phi\left(p, x_{n}\right)+\left(L r_{n}-\frac{1}{\mu}\right)\left[\left\|y_{n}-x_{n}\right\|^{2}+\left\|u_{n}-y_{n}\right\|^{2}\right] .
\end{aligned}
$$

Likewise, we obtain that

$$
\phi\left(p, v_{n}\right) \leq \phi\left(p, x_{n}\right)+\left(L r_{n}-\frac{1}{\mu}\right)\left[\left\|z_{n}-x_{n}\right\|^{2}+\left\|v_{n}-z_{n}\right\|^{2}\right] .
$$


Now, from (3.1), (3.7), (3.8), Lemma 2.2, Lemma 2.6 and the fact that $L \gamma_{n}-\frac{1}{\mu}<0$, we have the following:

$$
\begin{aligned}
\phi\left(p, x_{n+1}\right)= & \phi\left(p, \Pi_{C} J^{-1}\left(\alpha_{n} J u+\left(1-\alpha_{n}\right) w_{n}\right)\right) \\
\leq & \phi\left(p, J^{-1}\left(\alpha_{n} J u+\left(1-\alpha_{n}\right) w_{n}\right)\right) \\
= & \phi\left(p, J^{-1}\left(\alpha_{n} J u+\left(1-\alpha_{n}\right)\left[a_{n} J x_{n}+b_{n} J T x_{n}+c_{n} J u_{n}+d_{n} J v_{n}\right]\right)\right) \\
\leq & \alpha_{n} \phi(p, u)+\left(1-\alpha_{n}\right)\left[a_{n} \phi\left(p, x_{n}\right)+b_{n} \phi\left(p, x_{n}\right)+c_{n} \phi\left(p, u_{n}\right)\right. \\
& \left.+d_{n} \phi\left(p, v_{n}\right)-a_{n} b_{n} g\left(\left\|J T x_{n}-J x_{n}\right\|\right)\right] \\
\leq & \alpha_{n} \phi(p, u)+\left(1-\alpha_{n}\right) \phi\left(p, x_{n}\right)-\left(1-\alpha_{n}\right) a_{n} b_{n} g\left(\left\|J T x_{n}-J x_{n}\right\|\right) \\
& +\left(1-\alpha_{n}\right)\left(L \gamma_{n}-\frac{1}{\mu}\right)\left[c_{n}\left(\left\|u_{n}-y_{n}\right\|^{2}+\left\|y_{n}-x_{n}\right\|^{2}\right)\right. \\
& \left.+d_{n}\left(\left\|v_{n}-z_{n}\right\|^{2}+\left\|z_{n}-x_{n}\right\|^{2}\right)\right] \\
\leq & \alpha_{n} \phi(p, u)+\left(1-\alpha_{n}\right) \phi\left(p, x_{n}\right) .
\end{aligned}
$$

Therefore, by induction we get that

$$
\phi\left(p, x_{n+1}\right) \leq \max \left\{\phi(p, u), \phi\left(p, x_{0}\right)\right\}, \quad \forall n \geq 0,
$$

which implies that $\left\{x_{n}\right\},\left\{y_{n}\right\},\left\{z_{n}\right\},\left\{u_{n}\right\}$ and $\left\{v_{n}\right\}$ are bounded.

Let $x^{*}=\Pi_{\mathcal{F}} u$ and $t_{n}=J^{-1}\left(\alpha_{n} J u+\left(1-\alpha_{n}\right) w_{n}\right)$. Then, using (3.1), Lemma 2.2, Lemma 2.3 and the fact that $L \gamma_{n}-\frac{1}{\mu}<0$, we obtain

$$
\begin{aligned}
\phi\left(x^{*}, x_{n+1}\right)= & \phi\left(x^{*}, \Pi_{C} J^{-1}\left(\alpha_{n} J u+\left(1-\alpha_{n}\right) w_{n}\right)\right) \\
\leq & \phi\left(x^{*}, J^{-1}\left(\alpha_{n} J u+\left(1-\alpha_{n}\right)\left[a_{n} J x_{n}+b_{n} J T x_{n}+c_{n} J u_{n}+d_{n} J v_{n}\right]\right)\right) \\
= & V\left(x^{*}, \alpha_{n} J u+\left(1-\alpha_{n}\right)\left[a_{n} J x_{n}+b_{n} J T x_{n}+c_{n} J u_{n}+d_{n} J v_{n}\right]\right) \\
\leq & V\left(x^{*},\left(1-\alpha_{n}\right)\left[a_{n} J x_{n}+b_{n} J T x_{n}+c_{n} J u_{n}+d_{n} J v_{n}\right]+\alpha_{n} J x^{*}\right) \\
& -2\left\langle t_{n}-x^{*}, \alpha_{n}\left(J x^{*}-J u\right)\right\rangle,
\end{aligned}
$$

and

$$
\begin{aligned}
\phi\left(x^{*}, x_{n+1}\right) \leq & \left(1-\alpha_{n}\right)\left[a_{n} \phi\left(x^{*}, x_{n}\right)+b_{n} \phi\left(x^{*}, x_{n}\right)+c_{n} \phi\left(x^{*}, u_{n}\right)+d_{n} \phi\left(x^{*}, v_{n}\right)\right] \\
& -\left(1-\alpha_{n}\right) a_{n} b_{n} g\left(\left\|J T x_{n}-J x_{n}\right\|\right)+2 \alpha_{n}\left\langle t_{n}-x^{*}, J u-J x^{*}\right\rangle \\
\leq & \left(1-\alpha_{n}\right) \phi\left(x^{*}, x_{n}\right)+\left(1-\alpha_{n}\right)\left(L \gamma_{n}-\frac{1}{\mu}\right) \\
& \times\left[c_{n}\left(\left\|u_{n}-y_{n}\right\|^{2}+\left\|y_{n}-x_{n}\right\|^{2}\right)+d_{n}\left(\left\|v_{n}-z_{n}\right\|^{2}+\left\|z_{n}-x_{n}\right\|^{2}\right)\right] \\
& -\left(1-\alpha_{n}\right) a_{n} b_{n} g\left(\left\|J T x_{n}-J x_{n}\right\|\right)+2 \alpha_{n}\left\langle t_{n}-x^{*}, J u-J x^{*}\right\rangle \\
\leq & \left(1-\alpha_{n}\right) \phi\left(x^{*}, x_{n}\right)+2 \alpha_{n}\left\langle t_{n}-x^{*}, J u-J x^{*}\right\rangle \\
= & \left(1-\alpha_{n}\right) \phi\left(x^{*}, x_{n}\right)+2 \alpha_{n}\left\langle t_{n}-x_{n}, J u-J x^{*}\right\rangle \\
& +2 \alpha_{n}\left\langle x_{n}-x^{*}, J u-J x^{*}\right\rangle \\
\leq & \left(1-\alpha_{n}\right) \phi\left(x^{*}, x_{n}\right)+2 \alpha_{n}\left\|t_{n}-x_{n}\right\|\left\|J u-J x^{*}\right\| \\
& +2 \alpha_{n}\left\langle x_{n}-x^{*}, J u-J x^{*}\right\rangle .
\end{aligned}
$$

Now, we consider two cases.

Case 1 Suppose that there exists $n_{0} \in \mathbb{N}$ such that $\left\{\phi\left(x^{*}, x_{n}\right)\right\}$ is decreasing for all $n \geq n_{0}$. Then, we get that $\left\{\phi\left(x^{*}, x_{n}\right)\right\}$ is convergent. Thus, from (3.10) and the fact that $a_{n}, b_{n}, c_{n}, d_{n} \geq e>0, \gamma_{n}<b<\frac{1}{\mu L}$ for all $n \geq 0$ and $\alpha_{n} \rightarrow 0$ as $n \rightarrow \infty$, we have that

$$
\begin{aligned}
& u_{n}-y_{n} \rightarrow 0, y_{n}-x_{n} \rightarrow 0, z_{n}-v_{n} \rightarrow 0, \\
& z_{n}-x_{n} \rightarrow 0, J T x_{n}-J x_{n} \rightarrow 0 \quad \text { as } \quad n \rightarrow \infty .
\end{aligned}
$$

As $E^{*}$ is uniformly smooth, $J^{-1}$ is uniformly continuous on bounded subsets of $E^{*}$ and hence we obtain 


$$
J^{-1}\left(J T x_{n}\right)-J^{-1}\left(J x_{n}\right)=T x_{n}-x_{n} \rightarrow 0 \text { as } n \rightarrow \infty .
$$

Moreover, by the property of $\phi$, we have

$$
\begin{aligned}
\phi\left(x_{n}, t_{n}\right)= & \phi\left(x_{n}, J^{-1}\left(\alpha_{n} J u+\left(1-\alpha_{n}\right)\left[a_{n} J x_{n}+b_{n} J T x_{n}+c_{n} J u_{n}+d_{n} J v_{n}\right]\right)\right) \\
\leq & \alpha_{n} \phi\left(x_{n}, u\right)+\left(1-\alpha_{n}\right)\left[a_{n} \phi\left(x_{n}, x_{n}\right)+b_{n} \phi\left(x_{n}, T x_{n}\right)\right. \\
& \left.+c_{n} \phi\left(x_{n}, u_{n}\right)+d_{n} \phi\left(x_{n}, v_{n}\right)\right] .
\end{aligned}
$$

This together with (2.3), (3.12) and (3.13) implies that

$$
\phi\left(x_{n}, t_{n}\right) \rightarrow 0 \text { as } n \rightarrow \infty
$$

which in turn implies that

$$
x_{n}-t_{n} \rightarrow 0 \text { as } n \rightarrow \infty .
$$

Furthermore, since $\left\{x_{n}\right\}$ is bounded subset of $E$ which is reflexive, we can choose a subsequence $\left\{x_{n_{j}}\right\}$ of $\left\{x_{n}\right\}$ such that $x_{n_{j}} \rightarrow z$ and $\lim \sup _{n \rightarrow \infty}\left\langle x_{n}-x^{*}, J u-J x^{*}\right\rangle=\lim _{j \rightarrow \infty}\left\langle x_{n_{j}}-x^{*}, J u-J x^{*}\right\rangle$. This implies from (3.12) that $z_{n_{j}} \rightarrow z, y_{n_{j}} \rightarrow z, u_{n_{j}} \rightarrow z$ and $v_{n_{j}} \rightarrow z$ as $j \rightarrow \infty$.

Note that relatively nonexpansiveness of $T$ implies that $z \in F(T)$.

Now, we show that $z \in \cap_{i=1}^{2} \operatorname{VI}\left(C, A_{i}\right)$. Since $A_{i}$, for each $i \in\{1,2\}$, is Lipschitz continuous, we have

$$
\left\|A_{1} u_{n_{j}}-A_{1} y_{n_{j}}\right\| \rightarrow 0 \text { as } j \rightarrow \infty \text {. }
$$

Now, let

$$
B_{1} x=\left\{\begin{array}{lll}
A_{1} x+N_{C} x, & \text { if } & x \in C, \\
\emptyset, & \text { if } \quad x \notin C,
\end{array}\right.
$$

where $N_{C}(x)$ is the normal cone to $C$ at $x \in C$ given by $N_{C}(x)=\left\{w \in E^{*}:\langle x-u, w\rangle \geq 0\right.$ for all $\left.u \in C\right\}$. Then, $B_{1}$ is maximal monotone and $0 \in B_{1} x$ if and only if $x \in V I\left(C, A_{1}\right)$ (see, e.g. [21]). Let $(v, w) \in G\left(B_{1}\right)$. Then, we have $w \in B_{1} v=A_{1} v+N_{C} v$ and hence $w-A_{1} v \in N_{C} v$. Thus, we get $\left\langle v-u, w-A_{1} v\right\rangle \geq 0$, for all $u \in C$. On the other hand, since $u_{n_{j}}=\Pi_{C} J^{-1}\left(J x_{n_{j}}-\gamma_{n_{j}} A_{1} y_{n_{j}}\right)$ and $v \in C$, we have $\left\langle J x_{n_{j}}-\gamma_{n_{j}} A_{1} y_{n_{j}}-\right.$ $\left.J u_{n_{j}}, u_{n_{j}}-v\right\rangle \geq 0$, and hence $\left\langle v-u_{n_{j}},\left(J u_{n_{j}}-J x_{n_{j}}\right) / \gamma_{n_{j}}+A_{1} y_{n_{j}}\right\rangle \geq 0$. Thus, as $u_{n_{j}} \in C$, the above imply that

$$
\begin{aligned}
\left\langle v-u_{n_{j}}, w\right\rangle \geq & \left\langle v-u_{n_{j}}, A_{1} v\right\rangle \\
\geq & \left\langle v-u_{n_{j}}, A_{1} v\right\rangle-\left\langle v-u_{n_{j}},\left(J u_{n_{j}}-J x_{n_{j}}\right) / \gamma_{n_{j}}+A_{1} y_{n_{j}}\right\rangle \\
= & \left\langle v-u_{n_{j}}, A_{1} v-A_{1} u_{n_{j}}\right\rangle+\left\langle v-u_{n_{j}}, A_{1} u_{n_{j}}-A_{1} y_{n_{j}}\right\rangle \\
& -\left\langle v-u_{n_{j}},\left(J u_{n_{j}}-J x_{n_{j}}\right) / \gamma_{n_{j}}\right\rangle \\
\geq & \left\langle v-u_{n_{j}}, A_{1} u_{n_{j}}-A_{1} y_{n_{j}}\right\rangle-\left\langle v-u_{n_{j}},\left(J u_{n_{j}}-J x_{n_{j}}\right) / \gamma_{n_{j}}\right\rangle .
\end{aligned}
$$

Therefore, since $E$ is uniformly smooth we have that $J$ is uniformly continuous and hence $J u_{n}-J x_{n} \rightarrow 0$. Thus, from (3.17) we get that $\langle v-z, w\rangle \geq 0$ as $j \rightarrow \infty$. Then, maximality of $B_{1}$ gives that $z \in B_{1}^{-1}(0)$. Therefore, $z \in \operatorname{VI}\left(C, A_{1}\right)$. Similarly, with the use of $v_{n_{j}}=\Pi_{C} J^{-1}\left(J x_{n_{j}}-\gamma_{n_{j}} A_{2} z_{n_{j}}\right)$ we get that $z \in$ $\operatorname{VI}\left(C, A_{2}\right)$. Thus, we have that $z \in \operatorname{VI}\left(C, A_{1}\right) \cap \operatorname{VI}\left(C, A_{2}\right) \cap F(T)$. Therefore, by Lemma 2.4, we immediately obtain that

$$
\begin{aligned}
\limsup _{n \rightarrow \infty}\left\langle x_{n}-x^{*}, J u-J x^{*}\right\rangle & =\lim _{j \rightarrow \infty}\left\langle x_{n_{j}}-x^{*}, J u-J x^{*}\right\rangle \\
& =\left\langle z-x^{*}, J u-J x^{*}\right\rangle \leq 0 .
\end{aligned}
$$

Hence, it follows from (3.11), (3.15), (3.18) and Lemma 2.9 that $\phi\left(x^{*}, x_{n}\right) \rightarrow 0$ as $n \rightarrow \infty$. Then, Lemma 2.7 implies that $x_{n} \rightarrow x^{*}=\Pi_{\mathcal{F}} u$.

Case 2 Suppose that there exists a subsequence $\left\{n_{i}\right\}$ of $\{n\}$ such that

$$
\phi\left(x^{*}, x_{n_{i}}\right)<\phi\left(x^{*}, x_{n_{i}+1}\right),
$$

for all $i \in \mathbb{N}$. Then, by Lemma 2.10, there exists a nondecreasing sequence $\left\{m_{k}\right\} \subset \mathbb{N}$ such that $m_{k} \rightarrow \infty$, and 


$$
\phi\left(x^{*}, x_{m_{k}}\right) \leq \phi\left(x^{*}, x_{m_{k}+1}\right) \text { and } \phi\left(x^{*}, x_{k}\right) \leq \phi\left(x^{*}, x_{m_{k}+1}\right),
$$

for all $k \in \mathbb{N}$. Now, from (3.10) and the fact that $a_{n}, b_{n}, c_{n}, d_{n} \geq e>0, \gamma_{n}<b<\frac{1}{\mu L}$ for all $n \geq 0$ and $\alpha_{n} \rightarrow 0$ as $n \rightarrow \infty$, we get that $u_{m_{k}}-y_{m_{k}} \rightarrow 0, y_{m_{k}}-x_{m_{k}} \rightarrow 0, z_{m_{k}}-v_{m_{k}} \rightarrow 0, z_{m_{k}}-x_{m_{k}} \rightarrow 0, J T x_{m_{k}}-J x_{m_{k}} \rightarrow 0$ as $k \rightarrow \infty$. Thus, following the method in Case 1, we obtain

$$
\limsup _{k \rightarrow \infty}\left\langle x_{m_{k}}-x^{*}, J u-J x^{*}\right\rangle \leq 0 .
$$

Now, from (3.11), we have that

$$
\begin{aligned}
\phi\left(x^{*}, x_{m_{k}+1}\right) \leq & \left(1-\alpha_{m_{k}}\right) \phi\left(x^{*}, x_{m_{k}}\right)+2 \alpha_{m_{k}}\left\langle x_{m_{k}}-x^{*}, J u-J x^{*}\right\rangle \\
& +2 \alpha_{m_{k}}\left\|t_{m_{k}}-x_{m_{k}}\right\| .\left\|J u-J x^{*}\right\|,
\end{aligned}
$$

and hence (3.19) and (3.21) imply that

$$
\begin{aligned}
\alpha_{m_{k}} \phi\left(x^{*}, x_{m_{k}}\right) \leq & \phi\left(x^{*}, x_{m k}\right)-\phi\left(x^{*}, x_{m_{k}+1}\right)+2 \alpha_{m_{k}}\left\langle x_{m_{k}}-x^{*}, J u-J x^{*}\right\rangle \\
& +2 \alpha_{m_{k}}\left\|t_{m_{k}}-x_{m_{k}}\right\| .\left\|J u-J x^{*}\right\| \\
\leq & 2 \alpha_{m_{k}}\left\langle x_{m_{k}}-x^{*}, J u-J x^{*}\right\rangle \\
& +2 \alpha_{m_{k}}\left\|t_{m_{k}}-x_{m_{k}}\right\| .\left\|J u-J x^{*}\right\| .
\end{aligned}
$$

But the fact that $\alpha_{m_{k}}>0$ implies that

$$
\phi\left(x^{*}, x_{m_{k}}\right) \leq 2\left\langle x_{m_{k}}-x^{*}, J u-J x^{*}\right\rangle+2\left\|t_{m_{k}}-x_{m_{k}}\right\| .\left\|J u-J x^{*}\right\| .
$$

Thus, using (3.15) and (3.20) we get that $\phi\left(x^{*}, x_{m_{k}}\right) \rightarrow 0$ as $k \rightarrow \infty$. This together with (3.21) implies that $\phi\left(x^{*}, x_{m_{k}+1}\right) \rightarrow 0$ as $k \rightarrow \infty$. But $\phi\left(x^{*}, x_{k}\right) \leq \phi\left(x^{*}, x_{m_{k}+1}\right)$ for all $k \in \mathbb{N}$ gives that $x_{k} \rightarrow x^{*}$. Therefore, from the above two cases, we can conclude that $\left\{x_{n}\right\}$ converges strongly to a point $x^{*}=\Pi_{\mathcal{F}} u$. The proof is complete.

If, in Theorem 3.1, we assume that $T=I$, the identity mapping on $C$, then we obtain the following corollary.

Corollary 3.2 Let $C$ be a nonempty, closed and convex subset of a 2-uniformly convex and uniformly smooth real Banach space E. Let $A_{i}: C \rightarrow E^{*}$ be $L_{i}$-Lipschitz monotone mappings with Lipschitz constants $L_{i}$, for $i=1,2$. Let $u$ be any point in $C$. Assume that $\mathcal{F}=V I\left(C, A_{1}\right) \cap V I\left(C, A_{2}\right)$ is nonempty. Let $\left\{x_{n}\right\}$ be a sequence generated from an arbitrary $x_{0} \in C$ by

$$
\left\{\begin{array}{l}
z_{n}=\Pi_{C} J^{-1}\left[J x_{n}-\gamma_{n} A_{2} x_{n}\right], \\
y_{n}=\Pi_{C} J^{-1}\left[J x_{n}-\gamma_{n} A_{1} x_{n}\right], \\
w_{n}=a_{n} J x_{n}+b_{n} J\left(u_{n}\right)+c_{n} J\left(v_{n}\right), \\
x_{n+1}=\Pi_{C} J^{-1}\left[\alpha_{n} J u+\left(1-\alpha_{n}\right) w_{n}\right],
\end{array}\right.
$$

where $\left.u_{n}=\Pi_{C} J^{-1}\left[J x_{n}-\gamma_{n} A_{1} y_{n}\right]\right), v_{n}=\Pi_{C} J^{-1}\left[J x_{n}-\gamma_{n} A_{2} z_{n}\right],\left\{\gamma_{n}\right\} \subset[a, b] \subset\left(0, \frac{1}{\mu L}\right)$, for $L:=$ $\max \left\{L_{1}, L_{2}\right\}$ and $\left\{a_{n}\right\},\left\{b_{n}\right\},\left\{c_{n}\right\} \subset[e, 1) \subset(0,1)$ such that $a_{n}+b_{n}+c_{n}=1$. Then, $\left\{x_{n}\right\}$ converges strongly to a point $x^{*}$ in $\mathcal{F}$ which is nearest to $u$ with respect to the Lyapunov distance.

If, in Corollary 3.2, we consider $A_{1}=0$ or $A_{2}=0$, then we obtain the following corollary for one variational inequality problem for a monotone mapping $A$.

Corollary 3.3 Let $C$ be a nonempty, closed and convex subset of a rm 2-uniformly convex and uniformly smooth real Banach space E. Let $A: C \rightarrow E^{*}$ be a Lipschitz monotone mapping with Lipschitz constant $L$ and let $u$ be any point in $C$. Assume that VI $(C, A)$ is nonempty. Let $\left\{x_{n}\right\}$ be a sequence generated from an arbitrary $x_{0} \in C$ by

$$
\left\{\begin{array}{l}
y_{n}=\Pi_{C} J^{-1}\left[J x_{n}-\gamma_{n} A x_{n}\right], \\
x_{n+1}=\Pi_{C} J^{-1}\left[\alpha_{n} J u+\left(1-\alpha_{n}\right)\left(a_{n} J x_{n}+\left(1-a_{n}\right) J\left(u_{n}\right)\right)\right],
\end{array}\right.
$$

where, $u_{n}=\Pi_{C} J^{-1}\left[J x_{n}-\gamma_{n} A y_{n}\right],\left\{\gamma_{n}\right\} \subset[a, b] \subset\left(0, \frac{1}{\mu L}\right)$ and $\left\{a_{n}\right\} \subset[e, 1) \subset(0,1)$. Then, $\left\{x_{n}\right\}$ converges strongly to a point $x^{*}$ in $\mathcal{F}$ which is nearest to $u$ with respect to the Lyapunov distance. 
If, in Theorem 3.1, we assume that $A_{i}$, for $i=1,2$, are $\gamma_{i}$-inverse strongly monotone mappings, then both are $L$-Lipschitz with constant $L=\max \left\{\frac{1}{\gamma_{1}}, \frac{1}{\gamma_{2}}\right\}$ and hence we get the following corollary.

Corollary 3.4 Let $C$ be a nonempty, closed and convex subset of a 2-uniformly convex and uniformly smooth real Banach space E. Let $A_{i}: C \rightarrow E^{*}$ be an $\gamma_{i}$-inverse strongly monotone mappings, for $i=1,2$. Let $T: C \rightarrow C$ be relatively nonexpansive mapping. Assume that $\mathcal{F}=V I\left(C, A_{1}\right) \cap V I\left(C, A_{2}\right) \cap F(T)$ is nonempty. Let $\left\{x_{n}\right\}$ be a sequence generated from an arbitrary $u, x_{0} \in C$ by

$$
\left\{\begin{array}{l}
z_{n}=\Pi_{C} J^{-1}\left[J x_{n}-\gamma_{n} A_{2} x_{n}\right], \\
y_{n}=\Pi_{C} J^{-1}\left[J x_{n}-\gamma_{n} A_{1} x_{n}\right], \\
w_{n}=a_{n} J x_{n}+b_{n} J T x_{n}+c_{n} J\left(u_{n}\right)+d_{n} J\left(v_{n}\right), \\
x_{n+1}=\Pi_{C} J^{-1}\left[\alpha_{n} J u+\left(1-\alpha_{n}\right) w_{n}\right]
\end{array}\right.
$$

where $\left.u_{n}=\Pi_{C} J^{-1}\left[J x_{n}-\gamma_{n} A_{1} y_{n}\right]\right), v_{n}=\Pi_{C} J^{-1}\left[J x_{n}-\gamma_{n} A_{2} z_{n}\right],\left\{\gamma_{n}\right\} \subset[a, b] \subset\left(0, \frac{1}{\mu L}\right)$, for $L:=$ $\max \left\{\frac{1}{\gamma_{1}}, \frac{1}{\gamma_{2}}\right\}$, and $\left\{a_{n}\right\},\left\{b_{n}\right\},\left\{c_{n}\right\},\left\{d_{n}\right\} \subset[e, 1) \subset(0,1)$ such that $a_{n}+b_{n}+c_{n}+d_{n}=1$. Then, $\left\{x_{n}\right\}$ converges strongly to a point $x^{*}$ in $\mathcal{F}$ which is nearest to $u$ with respect to the Lyapunov distance.

If, in Theorem 3.1, we assume that $C=E$, then the projection mapping $\Pi_{C}$ is reduced to the identity mapping in $E$ and $\operatorname{VI}\left(C, A_{1}\right)=A_{1}^{-1}(0), \operatorname{VI}\left(C, A_{2}\right)=A_{2}^{-1}(0)$. Thus, we get the following corollary.

Corollary 3.5 Let $E$ be a 2-uniformly convex and uniformly smooth real Banach space $E$. Let $A_{i}: E \rightarrow E^{*}$ be $L_{i}$-Lipschitz monotone mappings with Lipschitz constants $L_{i}$, for $i=1,2$. Let $T: E \rightarrow E$ be relatively nonexpansive mapping. Assume that $\mathcal{F}=A_{1}^{-1}(0) \cap A_{2}^{-1}(0) \cap F(T)$ is nonempty. Let $\left\{x_{n}\right\}$ be a sequence generated from an arbitrary $u, x_{0} \in C$ by

$$
\left\{\begin{array}{l}
z_{n}=J^{-1}\left[J x_{n}-\gamma_{n} A_{2} x_{n}\right], \\
y_{n}=J^{-1}\left[J x_{n}-\gamma_{n} A_{1} x_{n}\right], \\
w_{n}=a_{n} J x_{n}+b_{n} J T x_{n}+c_{n} J\left(u_{n}\right)+d_{n} J\left(v_{n}\right), \\
x_{n+1}=J^{-1}\left[\alpha_{n} J u+\left(1-\alpha_{n}\right) w_{n}\right],
\end{array}\right.
$$

where $\left.u_{n}=J^{-1}\left[J x_{n}-\gamma_{n} A_{1} y_{n}\right]\right), v_{n}=J^{-1}\left[J x_{n}-\gamma_{n} A_{2} z_{n}\right],\left\{\gamma_{n}\right\} \subset[a, b] \subset\left(0, \frac{1}{\mu L}\right)$, for $L:=\max \left\{L_{1}, L_{2}\right\}$ and $\left\{a_{n}\right\},\left\{b_{n}\right\},\left\{c_{n}\right\},\left\{d_{n}\right\} \subset[e, 1) \subset(0,1)$ such that $a_{n}+b_{n}+c_{n}+d_{n}=1$. Then, $\left\{x_{n}\right\}$ converges strongly to a point $x^{*}$ in $\mathcal{F}$ which is nearest to $u$ with respect to the Lyapunov distance.

We note that the method of proof of Theorem 3.1 provides a convergence theorem for a finite family of Lipschitzian monotone mappings. In fact, we have the following theorem.

Theorem 3.6 Let $C$ be a nonempty, closed and convex subset of a 2-uniformly convex and uniformly smooth real Banach space E. Let $A_{i}: C \rightarrow E^{*}$ be $L_{i}$-Lipschitz monotone mappings with Lipschitz constants $L_{i}$, for $i=$ $2,3, \ldots, N$. Let $T: C \rightarrow C$ be relatively nonexpansive mapping. Assume that $\mathcal{F}=\cap_{i=2}^{\mathbf{N}} V I\left(C, A_{i}\right) \cap F(T)$ is nonempty. Let $\left\{x_{n}\right\}$ be a sequence generated from an arbitrary $u, x_{0} \in C$ by

$$
\left\{\begin{array}{l}
y_{n i}=\Pi_{C} J^{-1}\left[J x_{n}-\gamma_{n} A_{i} x_{n}\right], \\
x_{n+1}=\Pi_{C} J^{-1}\left[\alpha_{n} J u+\left(1-\alpha_{n}\right)\left(b_{n 0} J x_{n}+b_{n 1} J T x_{n}+\sum_{i=2}^{N} b_{n i} J\left(u_{n i}\right)\right)\right],
\end{array}\right.
$$

where $u_{n i}=\Pi_{C} J^{-1}\left[J x_{n}-\gamma_{n} A_{i} y_{n i}\right],\left\{\gamma_{n}\right\} \subset[a, b] \subset\left(0, \frac{1}{\mu L}\right)$, for $L:=\max \left\{L_{i}: i=2,3, \ldots, N\right\}$, $\left\{b_{n i}\right\} \subset[e, 1) \subset(0,1)$ such that $\sum_{i=0}^{N} b_{n i}=1$. Then, $\left\{x_{n}\right\}$ converges strongly to a point $x^{*}$ in $\mathcal{F}$ which is nearest to $u$ with respect to the Lyapunov distance.

We also note that the method of proof of Theorem 3.1 provides the following theorem for approximating the minimum-norm point of solution of two variational inequality problems. 
Theorem 3.7 Let $C$ be a nonempty, closed and convex subset of a 2-uniformly convex and uniformly smooth real Banach space E. Let $A_{i}: C \rightarrow E^{*}$ be an $L_{i}$-Lipschitz monotone mappings with Lipschitz constants $L_{i}$, for $i=1,2$. Assume that $\mathcal{F}=\cap_{i=1}^{2} V I\left(C, A_{i}\right)$ is nonempty. Let $\left\{x_{n}\right\}$ be a sequence generated from an arbitrary $x_{0} \in E$ by

$$
\left\{\begin{array}{l}
z_{n}=\Pi_{C} J^{-1}\left[J x_{n}-\gamma_{n} A_{2} x_{n}\right], \\
y_{n}=\Pi_{C} J^{-1}\left[J x_{n}-\gamma_{n} A_{1} x_{n}\right], \\
x_{n+1}=\Pi_{C} J^{-1}\left[\left(1-\alpha_{n}\right)\left(a_{n} J x_{n}+b_{n} J T x_{n}+c_{n} J\left(u_{n}\right)+d_{n} J\left(v_{n}\right)\right)\right],
\end{array}\right.
$$

where $u_{n}=\Pi_{C} J^{-1}\left[J x_{n}-\gamma_{n} A_{1} y_{n}\right], v_{n}=\Pi_{C} J^{-1}\left[J x_{n}-\gamma_{n} A_{2} z_{n}\right],\left\{\gamma_{n}\right\} \subset[a, b] \subset\left(0, \frac{1}{\mu L}\right)$, for $L:=$ $\max \left\{L_{1}, L_{2}\right\},\left\{a_{n}\right\},\left\{b_{n}\right\},\left\{c_{n}\right\},\left\{d_{n}\right\} \subset[e, 1) \subset(0,1)$ such that $a_{n}+b_{n}+c_{n}+d_{n}=1$. Then, $\left\{x_{n}\right\}$ converges strongly to a minimum-norm point $x^{*}$ of $\mathcal{F}$ with respect to the Lyapunov distance.

Remark 3.8 Theorem 3.1 extends Theorem 3.1 of Nadezhkina and Takahashi [17] in the sense that our scheme provides strong convergence to a common point of the fixed point set of a relatively nonexpansive mapping and solutions of two variational inequality problems for Lipschitz monotone mappings in spaces more general than Hilbert spaces.

Remark 3.9 Theorem 3.1 also extends Theorem 3.1 of Iiduka and Takahashi [10] and Theorem 3.2 of Zegeye et al. [33] in the sense that our scheme provides strong convergence to a common point of the fixed point set of a relatively nonexpansive mapping and solutions of two variational inequality problems for a more general class of Lipschitz monotone mappings in 2-uniformly convex and uniformly smooth real Banach spaces.

Remark 3.10 Corollary 3.2 extends Theorem 1 of Yao et al. [32] and Corollary 3.2 of Zegeye and Shahzad [38] in the sense that our scheme provides strong convergence to a common point of solutions of two variational inequality problems in spaces more general than Hilbert spaces.

\section{Numerical example}

Now, we give an example of a relatively nonexpansive mapping and two Lipschitzian monotone mappings satisfying Theorem 3.1 and some numerical experiment result to explain the conclusion of the theorem as follows:

Example 1 Let $H=\mathbb{R}$ with Euclidean norm. Let $C=[-1,2]$ and $T: C \rightarrow C$ be defined by

$$
T x= \begin{cases}x^{2}, & x \in[-1,0) \\ x, & x \in[0,2]\end{cases}
$$

and $A_{1}, A_{2}: C \rightarrow \mathbb{R}$ be defined by

$$
\begin{aligned}
& A_{1} x= \begin{cases}0, & x \in[-1,1], \\
(x-1)^{2}, & x \in(1,2] .\end{cases} \\
& A_{2} x= \begin{cases}2 x, & x \in[-1,0), \\
0, & x \in\left[0, \frac{1}{2}\right), \\
x-\frac{1}{2}, & x \in\left[\frac{1}{2}, 2\right] .\end{cases}
\end{aligned}
$$

Then, we observe that, $T$ is continuous and hence $F(T)=[0,2]=\widehat{F}(T)$.

Now, if $p \in F(T)$, then we have

$$
\phi(p, T x)= \begin{cases}\left(p-x^{2}\right)^{2}, & x \in[-1,0) \\ (p-x)^{2}, & x \in[0,2]\end{cases}
$$

and $\phi(p, x)=(p-x)^{2}$ for all $x \in[-1,2]$.

Thus, $\phi(p, T x) \leq \phi(p, x)$ for all $x \in[-1,2]$ and hence $T$ is relatively nonexpansive mapping which is not nonexpansive since for $x=-0.6$ and $y=-0.7$, we have $|T x-T y|=0.13>0.1=|x-y|$.

Moreover, we easily see that $A_{1}$ and $A_{2}$ are monotone mappings. Next, we show that $A_{1}$ is Lipschitz. 
Case 1 Let $x, y \in[-1,1]$. Then we have:

$$
\left|A_{1} x-A_{1} y\right|=|0-0|=0 \leq|x-y| .
$$

Case 2 Let $x \in[-1,1]$ and $y \in[1,2]$. Then we have:

$$
\left|A_{1} x-A_{1} y\right|=\left|0-(y-1)^{2}\right|=(y-1)^{2} \leq|y-x|=|x-y| .
$$

Case 3 Let $x, y \in[1,2]$. Then we have:

$$
\begin{aligned}
\left|A_{1} x-A_{1} y\right|=\left|(x-1)^{2}-(y-1)^{2}\right| & \leq\left|x^{2}-y^{2}\right|+2|x-y| \\
& \leq|x+y||x-y|+2|x-y| \\
& \leq 4|x-y|+2|x-y|=6|x-y| .
\end{aligned}
$$

From, Cases 1, 2 and 3 we conclude that $A_{1}$ is Lipschitz with Lipschitz constant $L_{1}=6$. Similarly, one can show that $A_{2}$ is Lipschitz mapping with Lipschitz constant $L_{2}=3$. It is also clear that $\operatorname{VI}\left(C, A_{1}\right) \cap \operatorname{VI}\left(C, A_{2}\right) \cap$ $F(T)=\left[0, \frac{1}{2}\right]$.

Now, if we take, $\alpha_{n}=\frac{1}{n+100}, \gamma_{n}=\frac{1}{n+200}+0.001, a_{n}=b_{n}=c_{n}=\frac{1}{n+100}+0.001, d_{n}=1-\frac{3}{n+100}-0.003$, and $u=1.0$, we observe that the conditions of Theorem 3.1 are satisfied and Scheme (3.1) reduces to

$$
\left\{\begin{array}{l}
z_{n}=P_{C}\left[x_{n}-\gamma_{n} A_{2} x_{n}\right] \\
y_{n}=P_{C}\left[x_{n}-\gamma_{n} A_{1} x_{n}\right] \\
x_{n+1}=\alpha_{n} u+\left(1-\alpha_{n}\right)\left(a_{n} x_{n}+b_{n} T x_{n}+c_{n} u_{n}+d_{n} v_{n}\right)
\end{array}\right.
$$

where $u_{n}=P_{C}\left[x_{n}-\gamma_{n} A_{1} y_{n}\right]$ and $v_{n}=P_{C}\left[x_{n}-\gamma_{n} A_{2} z_{n}\right]$. Thus, for $x_{0}=-0.8$, Scheme (4.7) converges strongly to $0.5=P_{\mathcal{F}}(u)$. See the following table and figure.

\begin{tabular}{llllllllll}
\hline$n$ & 0 & 184 & 1364 & 1365 & 3512 & 30,000 & 40,000 & 70,000 & 89,999 \\
\hline$x_{n}$ & -0.8000 & 0.0010 & 0.4999 & 0.5001 & 0.5854 & 0.5156 & 0.5119 & 0.5070 & 0.5054 \\
\hline
\end{tabular}

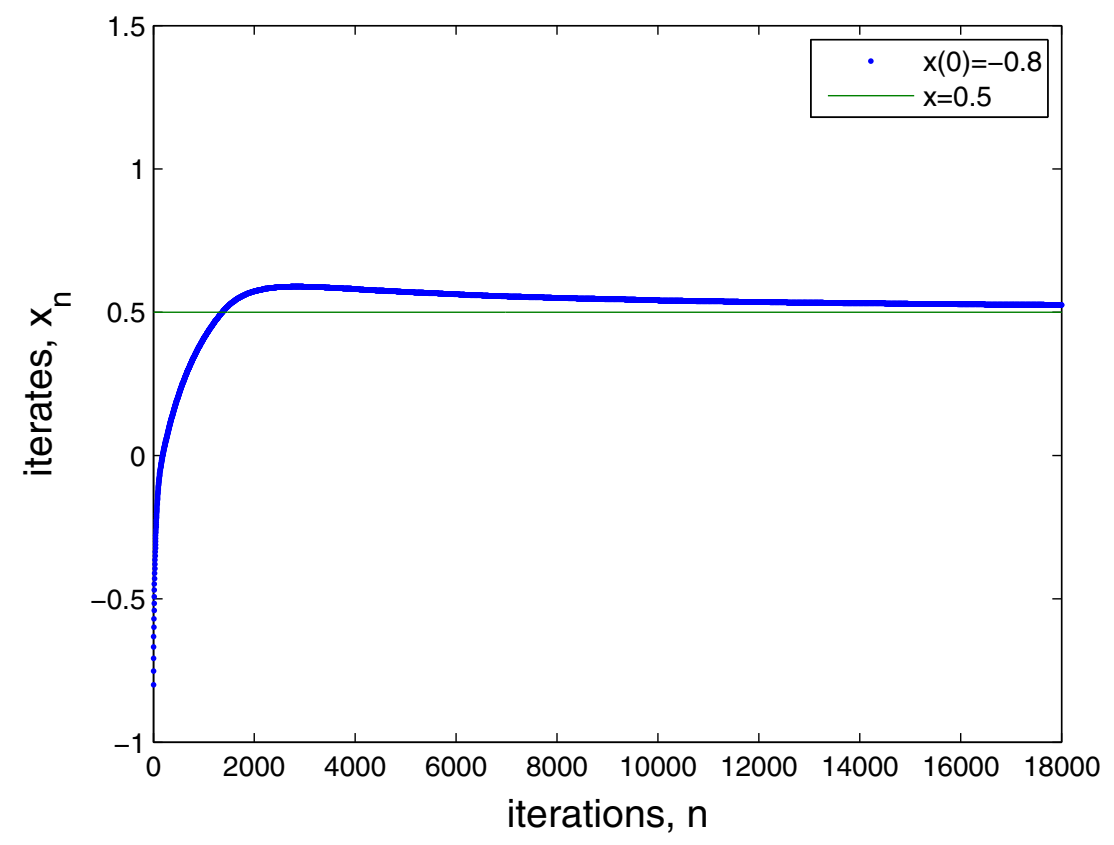


Acknowledgments The authors are grateful for useful comments from the referees. The authors are grateful to Simons Foundation based at University of Botswana for its financial support.

Open Access This article is distributed under the terms of the Creative Commons Attribution 4.0 International License (http:// creativecommons.org/licenses/by/4.0/), which permits unrestricted use, distribution, and reproduction in any medium, provided you give appropriate credit to the original author(s) and the source, provide a link to the Creative Commons license, and indicate if changes were made.

\section{References}

1. Alber, Ya.: Metric and generalized projection operators in Banach spaces: properties and applications, In: Kartsatos, A.G. (ed.) Theory and Applications of Nonlinear Operators of Accretive and Monotone Type. Lecture Notes in Pure and Appl. Math., vol. 178, pp. 15-50. Dekker, New York (1996)

2. Alber, Ya.; Iusem, A.N.: Extension of subgradient techniques for nonsmooth optimization in Banach spaces. Set-Valued Anal. 9, 315-335 (2001)

3. Aoyama,K.; Kohsaka, F.: Strongly relatively nonexpansive sequences generated by firmly nonexpansive-like mappings. Fixed Point Theory Appl. 2014, 95 (2014)

4. Bello Cruz, J.Y.; Iusem, A.N.: A strongly convergent direct method for monotone variational inequalities in Hilbert space. Numer. Funct. Anal. Optim. 30, 23-36 (2009)

5. Cai, G.; Bu, S.: An iterative algorithm for a general system of variational inequalities and fixed point problems in $q$-uniformly smooth Banach spaces. Optim. Lett. 7, 267-287 (2013)

6. Censor, Y.; Gibali, A.; Reich S.: Extensions of Korpelevichs extragradient method for the variational inequality problem in Euclidean space. Optimization (2010). doi:10.1080/02331934.2010.539689

7. Censor, Y.; Gibali, A.; Reich, S.: The subgradient extragradient method for solving variational inequalities in Hilbert space. J. Optim. Theory Appl. 148, 318-335 (2011)

8. Cioranescu, I.: Geometry of Banach Spaces, Duality Mappings and Nonlinear Problems. Kluwer Academic Publishers, Dordrecht (1990). MR 91m:46021

9. He, B.: A new method for a class of linear variational inequalities. Math. Progr. 66, 137-144 (1994)

10. Iiduka, H.; Takahashi, W.: Strong convergence theorems for nonexpansive mappings and inverse-strongly monotone mappings. Nonlinear Anal. 61, 341-350 (2005)

11. Iiduka, H.; Takahashi, W.; Toyoda, M.: Approximation of solutions of variational inequalities for monotone mappings. Panam. Math. J. 14, 49-61 (2004)

12. Kamimura, S.; Takahashi, W.: Strong convergence of proximal-type algorithm in a Banach space. SIAM J. Optim. 13, 938-945 (2002)

13. Kassay, G.; Reich, S.; Sabach, S.: Iterative methods for solving systems of variational inequalities in refelxive Banach spaces. SIAM J. Optim. 21, 1319-1344 (2011)

14. Korpelevich, G.M.: The extragradient method for finding saddle points and other problems. Matecon. 12, 747-756 (1976)

15. Kumam, P.: A hybrid approximation method for equilibrium and fixed point problems for a monotone mapping and a nonexpansive. Nonlinear Anal. Hybrid syst. (2008). doi:10.1016/j.nahs.2008.09.017

16. Mainge, P.E.: Strong convergence of projected subgradient methods for nonsmooth and non-strictly convex minimization. Set-Valued Anal. 16, 899-912 (2008)

17. Nadezhkina, N.; Takahashi, W.: Weak convergence theorem by an extragradient method for nonexpansive mappings and monotone mappings. J. Optim. Theory Appl. 128, 191-201 (2006)

18. Noor, M.A.: A class of new iterative methods for solving mixed variational inequalities. Math. Comput. Modell. 31, 11-19 (2000)

19. Reich, S.: A weak convergence theorem for the alternating method with Bregman distances. In: Theory and Applications of Nonlinear Operators of Accretive and Monotone Type, pp. 313-318. Marcel Dekker, New York (1996)

20. Reich, S.; Sabach, S.: Three strong convergence theorems regarding iterative methods for solving equilibrium problems in reflexive Banach spaces. Contemp. Math. 568, 225-240 (2012)

21. Rockafellar, R.T.: On the maximality of sums of nonlinear monotone operators. Trans. Am. Math. Soc. 149, 75-88 (1970)

22. Shahzad, N.; Zegeye, H.: Approximation methods for a common minimum-norm point of a solution of variational inequality and fixed point problems in Banach spaces. Bull. Korean Math. Soc. 51, 1 (2014)

23. Tada, A.; Takahashi, W.: Weak and strong convergence theorems for nonexpansive mappings and equilbrium problems. J. Optim. Theory Appl. 133, 359-370 (2007)

24. Takahashi, W.: Nonlinear Functional Analysis (Japanese). Kindikagaku, Tokyo (1988)

25. Takahashi, W.; Toyoda, M.: Weak convergence theorems for nonexpansive mappings and monotone mappings. J. Optim. Theory Appl. 118, 417-428 (2003)

26. Takahashi, W.; Zembayashi, K.: Strong and weak convergence theorems for equilibrium problems and relatively nonexpansive mappings in Banach spaces. Nonlinear Anal. 70, 45-57 (2009)

27. Xu, H.K.: Inequalities in Banach spaces with applictions. Nonlinear Anal. 16, 1127-1138 (1991)

28. Xu, H.K.: Another control condition in an iterative method for nonexpansive mappings. Bull. Aust. Math. Soc. 65, 109-113 (2002)

29. Yamada, I.: The hybrid steepest-descent method for variational inequality problems over the intersection of the fixed point sets of nonexpansive mappings. In: Butnariu, D.; Censor, Y.; Reich, S. (eds.) Inherently Parallel Algorithms in Feasibility and Optimization and Their Applications, pp. 473-504. North-Holland (2001)

30. Yao, Y.; Xu, H.-K.: Iterative methods for finding minimum-norm fixed points of nonexpansive mappings with applications. Optimization. 60(6), 645-658 (2011) 
31. Yao, Y.; Marino, G.; Muglia, L.: A modified Korpelevichs method convergent to the minimum norm solution of a variational inequality. Optimization (2012). doi:10.1080/02331934.2012.674947

32. Yao, Y.; Postolache, M.; Liou, Y-C.: Extragradient-type method for monotone variational inequalities. Fixed Point Theory Appl. 2013, 185 (2013)

33. Zegeye, H.; Ofoedu, E.U.; Shahzad, N.: Convergence theorems for equilibrium problem, variotional inequality problem and countably infinite relatively quasi-nonexpansive mappings. Appl. Math. Comput. 216, 3439-3449 (2010)

34. Zegeye, H.; Shahzad, N.: Strong convergence for monotone mappings and relatively weak nonexpansive mappings. Nonlinear Anal. 70, 2707-2716 (2009)

35. Zegeye, H.; Shahzad, N.: A hybrid scheme for finite families of equilibrium, variational inequality and fixed point problems. Nonlinear Anal. 74, 263-272 (2011)

36. Zegeye, H.; Shahzad, N.: An iteration to a common point of solution of variational inequality and fixed point-problems in Banach spaces. J. Appl. Math. 2012, 19 (2012), Article ID 504503

37. Zegeye, H.; Shahzad, N.: Extra gradient method for solutions of variational inequality problems in Banach spaces. Abstr. Appl. Anal. 2013, 8 (2013), Article ID 832548

38. Zegeye, H.; Shahzad, N.: Construction of a common solution of a finite family of variational inequality problems for monotone mappings in Banach spaces. Fixed Point Theory Appl. (2015) (submitted) 